\title{
Lung cancer screening practices among primary care providers in Northern Texas
}

\author{
Meng-Hua Tao ${ }^{*}$, Kimberly G Fulda ${ }^{2}$ and Long Wong ${ }^{3}$ \\ ${ }^{1}$ Department of Biostatistics and Epidemiology, University of North Texas Health Science Center, Fort Worth, Texas, USA \\ ${ }^{2}$ Department of Family Medicine and Osteopathic Manipulative Medicine; the North Texas Primary Care Practice-Based Research Network (NorTex), University \\ of North Texas Health Science Center, Fort Worth, Texas, USA \\ ${ }^{3}$ Department of Family Medicine and Osteopathic Manipulative Medicine, University of North Texas Health Science Center, Fort Worth, Texas,USA
}

\begin{abstract}
Background: The U.S. Preventive Services Task Forces (USPSTF) has recommended lung cancer screening with low-dose computed tomography (LDCT) in highrisk patients; however, the number of eligible patients receiving LDCT screening is still low. To understand current implementation and barriers to LDCT screening among primary care providers, a survey was conducted among members of the North Texas Primary Care Practice-Based Research Network (NorTex) between July and November 2018. The survey included questions regarding knowledge of lung cancer screening guidelines, perceptions, practice and barriers to LDCT screening. A total of 36 primary care providers completed the survey (response rate $=18 \%$ ).
\end{abstract}

Results: Overall, 69.4\% of respondents indicated that lung cancer screening with LDCT was recommended by USPSTF. 91.7\% of providers believed that the LDCT is effective in reducing lung cancer mortality for high-risk patients, while only $33.3 \%$ had referred most of high risk patients for LDCT screening in the past 12 months. Common perceived barriers to LDCT included concerns regarding insurance coverage, the cost of the test, and uncertainty of the benefits of the test.

Conclusions: Approximately $70 \%$ of primary care providers are familiar with the USPSTF guidelines for lung cancer screening and a number of providers' barriers to adherence to guideline are persistent. Further study of provider-based intervention is needed to improve screening implementation.

\section{Objective}

Lung cancer remains the leading cause of cancer deaths for men and women in the United States [1]; most lung cancers are diagnosed at a late stage when the cancer is more difficult to treat, resulting in a poor survival rate ranging from $10 \%$ to $20 \%$ [2]. The National Lung Screening Trial showed that lung cancer screening with low-dose computed tomography (LDCT) significantly reduced lung cancer mortality for high-risk current and former smokers [3]. Subsequently, the U.S. Preventive Services Task Forces (USPSTF) [4] and other professional organizations recommended screening for lung cancer with LDCT in high-risk persons. Moreover, from 2015, Medicare [5], the Affordable Care Act [6] and most private insurance companies [7] began to provide coverage for lung cancer screening with LDCT.

It was estimated that 6.8 million smokers were eligible for LDCT screening, while only $3.9 \%$ of eligible Americans reported receiving screening for lung cancer with LDCT in 2015[8]. Reasons for low uptake of screening may include gaps in patients' knowledge about the LDCT screening, lack of access to health care [9-11], and physicians' knowledge and perception regarding the screening recommendation and patient cost [11-18]. For most adult patients in the U.S., primary care providers (PCPs) play a critical role in offering preventive healthcare and screening; therefore, an understanding of PCPs' utilization and perceptions on lung cancer screening guidelines is necessary to improve appropriate assessment and referrals for specialty care services, as well as overall implementation of the screening procedure.

Five years after multiple screening guidelines included LDCT for lung cancer screening, we conducted a survey to understand current implementation of lung cancer LDCT screening among primary care providers so as to examine current barriers to adherence to the lung cancer screening guidelines.

\section{Methods}

Participants: We conducted a cross-sectional survey study within the North Texas Primary Care Practice-Based Research Network (NorTex). The NorTex is a primary care practice-based network (PBRN) which functions as a collaborative effort to conduct research among North Texas primary care practices. Utilizing this network, we surveyed primary care providers who were active members of NorTex between July and December 2018. Providers received up to three e-mails with a link to a confidential online survey using the Qualtrics Survey Platform. Eligible respondents were physicians, nurse practitioners and physician assistants who provided primary care services to patients 18 years of age or older in NorTex within the past 12 months. The study was approved by the University of North Texas Regional Institutional Review Board. All participants provided informed consent and were offered the chance to receive a $\$ 10$ gift card.

${ }^{*}$ Correspondence to: Meng-Hua Tao, Department of Biostatistics and Epidemiology, University of North Texas Health Science Center, 3500 Camp Bowie, Fort Worth, Texas, USA, Tel: 817-735-0520; Fax: 817-735-0446; E-mail: menghua.tao@unthsc.edu

Keywords: lung cancer screening, primary care provider, low-dose computed tomography, perception, barrier

Received: April 27, 2019; Accepted: May 09, 2019; Published: May 13, 2019 


\section{Questionnaire}

The survey was designed based on the National Cancer Institute (NCI) Colorectal and Lung Cancer Screening Questionnaire [19] and another prior survey of lung cancer conducted by Raz, et al. [13]. The survey included 56 items. Six multiple-choice items assessed primary care providers' perception of the effectiveness of LDCT, chest $\mathrm{x}$-ray and sputum cytology as screening tests for reducing lung cancer mortality in high-risk current or former smokers and in never smokers aged 55 years and older. In addition, six items assessed providers' perception of benefit and harm of LDCT in high-risk individuals compared to mammography. Eight items assessed lung cancer screening practices in the past 12 months for asymptomatic patients with LDCT, chest $\mathrm{x}$-ray or sputum cytology. Knowledge of the current guidelines for lung cancer screening was also assessed through four items. Barriers to lung cancer screening were further assessed by asking reasons why the providers may not refer patients for LDCT screening. Primary care providers' demographic and practice characteristics were also asked in the survey, including questions regarding practice location, percentage of patients in their practice who are insured, insured by the Affordable Care Act, Medicaid, Medicare, or private insurance.

\section{Statistical analysis}

Descriptive statistics were used to characterize provider and practice characteristics, general beliefs of effectiveness, guideline knowledge, barriers to lung cancer screening, and perception of LDCT screening compared with breast mammography. Chi-square test was used to evaluate differences in knowledge of the current guidelines between PCPs who ordered LDCT in the past 12 months and those who did not. All statistical analyses were performed in SAS (v.9.4. Cary, NC); a two-sided alpha level of 0.05 was used to indicate statistical significance.

\section{Result}

Of eligible providers within the NorTex network, 40 responded to the survey. Four of these failed to respond to any question of the survey, for a final response rate of $18 \%$. Demographic characteristics of respondents, practice setting and practice style characteristics are shown in Table 1 . Majority of PCPs were female (65.7\%), from family medicine $(77.8 \%)$ and reported practicing more than 10 years $(65.7 \%)$. Nine $(25 \%)$ respondents were practicing in a non-university hospital or clinic including community health clinics. $44.1 \%$ and $54.5 \%$ of PCPs reported that $26-100 \%$ of their patients were Hispanics and African Americans, and $58.3 \%$ reported that $26-100 \%$ of patients were insured by Medicare. In addition, $91.7 \%$ of PCPs knew that LDCT is available in their practice area, and $55.6 \%$ of them knew the availability of lung cancer screening programs in their practice area.

PCPs' beliefs about the effectiveness of screening tests at reducing lung cancer mortality varied by smoking status and test methods (Table 2). $91.7 \%$ of PCPs perceived LDCT as very or somewhat effective at reducing lung cancer mortality for current or former smokers, while $25 \%$ of PCPs also believed that LDCT was effective in never smokers. Meanwhile, a large proportion of PCPs also thought that chest X-ray was very or somewhat effective for current or former smoker (44.4\%) and for never smokers (28.6\%). Very few PCPs perceived sputum cytology as an effective lung cancer screening test for patients regardless of smoking status.

Two-thirds of PCPs reported that they had ever ordered LDCT for lung cancer screening in an asymptomatic patient in the past 12
Table 1. Characteristics of primary care providers

\begin{tabular}{|c|c|}
\hline & Number of participants (n, \%) \\
\hline \multicolumn{2}{|l|}{ Sex $x^{*}$} \\
\hline Female & $23(65.7)$ \\
\hline Male & $12(34.3)$ \\
\hline \multicolumn{2}{|l|}{ Race/ethnicity $^{*}$} \\
\hline Non-Hispanic white & $14(40.0)$ \\
\hline Non-Hispanic black & $4(11.4)$ \\
\hline Hispanic & $5(14.3)$ \\
\hline Asian & $11(31.4)$ \\
\hline Other $^{1}$ & $1(2.9)$ \\
\hline \multicolumn{2}{|l|}{ Practice background } \\
\hline Family practice & $28(77.8)$ \\
\hline Internal medicine & $6(16.7)$ \\
\hline Others & $2(5.5)$ \\
\hline \multicolumn{2}{|l|}{ Years in practice ${ }^{*}$} \\
\hline $0-10$ & $12(34.3)$ \\
\hline$\geq 11$ & $23(65.7)$ \\
\hline \multicolumn{2}{|l|}{ Main practice type } \\
\hline Full/part owner & $2(5.6)$ \\
\hline Large medical group/system & $9(25.0)$ \\
\hline University hospital/clinic & $16(44.4)$ \\
\hline Non-university hospital/clinic & $9(25.0)$ \\
\hline \multicolumn{2}{|l|}{ Percentage of Hispanic patients } \\
\hline $0-25$ & $16(47.1)$ \\
\hline $26-100$ & $15(44.1)$ \\
\hline Unknown & $3(8.8)$ \\
\hline \multicolumn{2}{|c|}{ Percentage of African American patients } \\
\hline $0-25$ & $12(36.4)$ \\
\hline $26-100$ & $18(54.5)$ \\
\hline Unknown & $3(9.1)$ \\
\hline \multicolumn{2}{|c|}{ Percentage of uninsured patients } \\
\hline $0-25$ & $20(55.5)$ \\
\hline $26-100$ & $14(38.9)$ \\
\hline Unknown & $2(5.6)$ \\
\hline \multicolumn{2}{|c|}{ Percentage of patients insured by Medicare } \\
\hline $0-25$ & $13(36.2)$ \\
\hline $26-100$ & $21(58.3)$ \\
\hline Unknown & $2(5.6)$ \\
\hline \multicolumn{2}{|c|}{ Percentage of patients insured by Affordable Care } \\
\hline $0-25$ & $25(69.4)$ \\
\hline $26-100$ & $6(16.7)$ \\
\hline Unknown & $5(13.9)$ \\
\hline
\end{tabular}

${ }^{1}$ Include Native Americans, and multiple race/ethnicities; "Missing response were excluded from these analyses.

months, while only one-third of PCPs had referred most or almost all high risk patients for lung cancer screening with LDCT during the same time period. $77.8 \%$ PCPs had initiated a discussion about the benefits and risks of lung cancer screening with asymptomatic patients in the past 12 months, $19(52.8 \%)$ responded having special notation/flag in chart or electronic reminder when a patient is due for lung cancer screening. Meanwhile, one PCP $(2.8 \%)$ reported to have asymptomatic patients self-referred to screening, and only $8.4 \%$ indicated that half or more of their high-risk patients asked whether they should be screened for lung cancer.

Perceived barriers to refer patients for LDCT lung cancer screening were also estimated among PCPs (data not shown). The most common barriers were the perception that lung cancer screening is not covered by insurance plans (65.7\%), expensive cost of the screening for their health care system (30.6\%), and the perception that benefits of lung 
Table 2. Primary care providers' lung cancer screening beliefs, self-reported practice, and patient influence

\begin{tabular}{|c|c|c|c|}
\hline Characteristics & $\begin{array}{l}\text { Yes } \\
(\mathbf{n}, \%)\end{array}$ & $\begin{array}{l}\text { No/Unsure } \\
(\text { (n, \%) }\end{array}$ & $\begin{array}{l}\text { Missing } \\
(\mathrm{n}, \%)\end{array}$ \\
\hline \multicolumn{4}{|l|}{ Primary care providers' beliefs } \\
\hline \multicolumn{4}{|l|}{ Believes LDCT is somewhat or very effective in reducing lung cancer mortality for } \\
\hline Current or former smokers & $33(91.7)$ & $2(5.5)$ & $1(2.8)$ \\
\hline Never smokers & $9(25.0)$ & $14(38.9)$ & $13(36.1)$ \\
\hline \multicolumn{4}{|l|}{ Believes chest $\mathrm{X}$-ray is somewhat or very effective in reducing lung cancer mortality for } \\
\hline Current or former smokers & $16(44.4)$ & $19(52.8)$ & $1(2.8)$ \\
\hline Never smokers & $8(28.6)$ & $20(71.4)$ & 8 \\
\hline \multicolumn{4}{|l|}{ Believes sputum cytology is somewhat or very effective in reducing lung cancer mortality for } \\
\hline Current or former smokers & $5(13.9)$ & $29(80.6)$ & $2(5.5)$ \\
\hline Never smokers & $1((2.8)$ & $21(58.3)$ & $14(38.9)$ \\
\hline \multicolumn{4}{|l|}{ Primary care providers' practice in the past 12 months } \\
\hline Ever ordered LDCT for lung cancer screening & $24(66.7)$ & $12(33.3)$ & - \\
\hline Ever ordered chest X-ray for lung cancer screening & $10(27.8)$ & $26(72.2)$ & - \\
\hline Ever refer an asymptomatic patient for lung cancer screening & $5(13.9)$ & $30(83.3)$ & $1(2.8)$ \\
\hline \multicolumn{4}{|l|}{ Referred most or almost all high risk patient for } \\
\hline LDCT for lung cancer screening & $12(33.3)$ & $24(66.7)$ & - \\
\hline Chest X-ray & $3(8.3)$ & $33(91.7)$ & - \\
\hline Initiated a discussion about the benefits and risks of lung cancer screening with patients & $28(77.8)$ & $8(22.2)$ & - \\
\hline $\begin{array}{l}\text { Primary care practice has a mechanism for reminders that a patient is due for lung cancer } \\
\text { screening }\end{array}$ & $19(52.8)$ & $16(44.4)$ & $1(2.8)$ \\
\hline \multicolumn{4}{|l|}{ Patients' influence } \\
\hline Patient self-referred to a lung cancer screening center & $1(2.8)$ & $34(94.4)$ & $1(2.8)$ \\
\hline \multicolumn{4}{|l|}{ Percentage of high-risk patients asked about lung cancer screening } \\
\hline None or few $(<10 \%)$ & $30(83.3)$ & & \\
\hline Some $(10-39 \%)$ & $3(8.3)$ & & \\
\hline Half $(40-59 \%)$ & $1(2.8)$ & & \\
\hline Most $(60-89 \%)$ & $1(2.8)$ & & \\
\hline Almost all $(\geq 90 \%)$ & $1(2.8)$ & & \\
\hline
\end{tabular}

Table 3. Primary care providers' perceptions of lung cancer screening with LDCT compared to breast mammography

\begin{tabular}{|l|c|c|}
\hline Survey question & $\begin{array}{c}\text { Strongly or somewhat } \\
\text { agree (n, \%) }\end{array}$ & $\begin{array}{c}\text { Strongly or somewhat } \\
\text { disagree (n, \%) }\end{array}$ \\
\hline Compared with breast mammography, lung cancer screening with LDCT & \\
\hline More effective at reducing cancer-specific mortality & $19(52.8)$ & $15(41.7)$ \\
\hline Less cost-effective* & $13(13.1)$ & $14(40.0)$ \\
\hline Associated with greater risks & $12(34.3)$ & $11(31.4)$ \\
\hline Not as important to my female patients & $8(22.2)$ & $10(27.8)$ \\
\hline Not something I think about as much when I see a current or former smoker & $9(25.0)$ & $8(22.2)$ \\
\hline Not something I feel as comfortable discussing & $11(34.4)$ & $18(50.0)$ \\
\hline
\end{tabular}

*Missing response were excluded from these analyses. N/A: Neither agree nor disagree

cancer screening were unclear (22.9\%). Other minor barriers included inadequate time for discussing risks and benefits with patients (14.3\%), no accessibility of LDCT in their affiliated facilities (11.4\%), negative effects of lung cancer screening on smoking cession among smokers (8.6\%), and high potential risks of LDCT to patients (5.7\%).

As shown in Table 3, compared with breast mammography, large percentages of PCPs strongly or somewhat agreed that LDCT lung cancer screening is more effective at reducing cancer specific-mortality (52.8\%), associated with greater risk $(34.3 \%)$, not considered when seeing a current or former smoker $(25.0 \%)$, or not important to their female patients (22.2\%). $13.1 \%$ and $13.9 \%$ of PCPs perceived LDCT as less cost-effective and uncomfortable to discuss it with their patients, respectively. Meanwhile, a large proportion of PCPs neither agreed nor disagreed with these comparisons, ranging from $41.7 \%$ to effectiveness of LDCT screening to $16.7 \%$ of being uncomfortable to discuss with patients.

Thirty-one (86.1\%) PCPs knew at least one of four national expert groups (USPSTF, National Comprehensive Cancer Network
(NCCN), American Cancer Society (ACS) and American Lung Association (ALA)) recommended the lung cancer screening with LDCT. Similar percentages of PCPs thought ACS (70.6\%) and USPSTP (69.4\%) recommended the LDCT for lung cancer screening for high risk persons; whereas only $47.1 \%$ knew that it was recommended by NCCN. More PCPs who never ordered LDCT for an asymptomatic patient in the past 12 months responded unknown or unsure about USPSTF guidelines for lung cancer screening than those who had ever ordered $(\mathrm{p}<0.01)$ (data not shown).

\section{Conclusion}

Lung cancer screening with LDCT has been recommended by multiple organizations and covered by various insurance plans for about five years. In this cross-sectional survey study, we aimed to better understand current knowledge, beliefs, practices and barriers to lung cancer screening with LDCT among primary care providers. Particularly, primary care providers who participated this survey were from diverse medical practicing systems, and most of their patients 
were minorities, who are more likely to face disparities in receipt of preventive screening and in lung cancer mortality [20].

Our results showed that over two-thirds of PCPs were aware of USPSTF recommendations and $94 \%$ believed LDCT as effective at reducing lung cancer mortality for current or former smokers. We found about $66.7 \%$ of PCPs reported ever ordering LDCT for lung cancer screening in asymptomatic patients, but only $33.3 \%$ of PCPs reported ever referring most or almost all of high risk patients in the past 12 months. We also identified a number of barriers to LDCT reported by providers, including concerns about insurance coverage, cost to the health care system, unclear screening benefits, inadequate time, and no accessibility of LDCT.

Findings from recent survey studies conducted between 2013-2017 among primary care providers or family physicians showed around $50 \%$ of providers being aware of USPSTF recommendation, but quite low awareness rate for the NCCN recommendation $[11,13,14,17]$. In our study, awareness of USPSTF and ACS recommended guidelines was consistently high among PCPs, but awareness of NCCN guideline was also high $(47.1 \%)$. In addition, compared with breast cancer screening, more than half of PCPs perceived effectiveness of LDCT in reducing lung cancer mortality for high-risk patients. Our data indicated a gradual uptake of guidelines on lung cancer screening from different organizations, as well as improved understanding of the benefits of LDCT screening in high-risk individuals, as compared to previous research $[13,14]$.

Consistent with results from recent studies $[13,17,21]$, we observed $66.7 \%$ of PCPs had ever ordered LDCT to screen asymptomatic patients for lung cancer in the past 12 months. Raz, et al [13] reported that $52 \%$ of providers ordered an LDCT to screen any asymptomatic patient and $21.1 \%$ referred most of their high-risk patients for lung cancer screening with LDCT.

Another national survey of primary care physicians reported that over $80 \%$ would recommend LDCT screening for a high-risk patient [17]. In our study, the referral rate for most high-risk patients was $33.3 \%$ in responded PCPs. Although our data suggested the improved utilization of LDCT over time, the referral rate was still low. Moreover, previous studies showed a lack of adequate LDCT screening awareness in high-risk patients $[10,13,16,17]$. Consistently, over $80 \%$ of PCPs reported having less than $10 \%$ of high-risk patients asked about lung cancer screening in the past 12 months in our study, which suggests that improvements in awareness and knowledge on lung cancer screening with LDCT among eligible populations are important to ensure successful implementation at the population level. Since February 2015, the Centers for Medicare \& Medicaid Services (CMS) has determined to cover the cost of lung cancer screening counseling and shared decision making visit [5]; therefore, primary care providerbased education can be an important approach to promote LDCT screening in high-risk patients. A recent study found significant improvement in knowledge of lung cancer screening in patients after a counseling and shared decision-making visit with PCPs [22].

Insurance coverage, cost to the health care system and unclear screening benefits were the three most commonly reported perceived barriers to LDCT in our study. From 2015, the cost of annual screening for lung cancer with LDCT for eligible high-risk to beneficiaries is covered by the CMS [5], as well as a covered benefit by the Affordable Care Act and most private insurances [7]. To counsel patients appropriately, primary care providers need not only to have a thorough understanding of the eligibility criteria, benefits and potential harm of LDCT screening in high-risk patients, but also to be familiar with cost of LDCT screening, and make correct coding for the insurance. In addition, a clear guideline or education on understanding CT screening results, documentation and management all may be needed for primary care providers to improve the utilization of LDCT.

Our study has several limitations. Although we had broad representation of primary care providers in the NorTex network, the response rate was only $18 \%$ and the overall sample size was small, which limited our ability to conduct stratified analyses by practice region and specialty. However, our response rate was comparable with the rates of previous surveys conducted among PCPs [13,17]. In addition, our survey was limited to primary care providers in the NorTex network, which included racially and ethnically diverse providers practicing in North and Central Texas region. There are likely to be regional practice patterns that reflect perception and utilization of lung cancer screening with LDCT by providers. These will limit our ability to generalize our results to primary care providers in Texas or other regions. Despite these limitations, our study focused on providers caring for a racially/ ethnically diverse population in North and Central Texas, which would have important implications for utilization of lung cancer screening in this region with large minority populations.

In summary, although PCPs appear to perceive USPSTF recommended guidelines and believe in the effectiveness of LDCT screening for high-risk patients, a small proportion of eligible patients are being referred for LDCT screening. This study also identified several providers' barriers that need to be overcome to improve screening implementation, and these may include provider education and targeted interventions.

\section{Conflict of interest}

No potential conflicts of interests were disclosed.

\section{Acknowledgement}

The study was conducted within the North Texas Primary Care Practice-Based Research Network (NorTex). We thank the primary care providers who participated in this study. We also thank the staffs of NorTex, Anna Espinoza, MD, and Omair Muzaffar, MPH, for their valuable contributions. This work was supported by the Texas Academy of Family Physician Foundation.

\section{References}

1. Siegel R, Miller KD, Jemal A (2018) Cancer statistics, 2018. CA Cancer J Clin 68 $7-30$.

2. Allemani C, Matsuda T, Di Carlo V, Harewood R, Matz M, et al. (2018) Global surveillance of trends in cancer survival 2000-14 (CONCORD-3): analysis of individual records for 37513025 patients diagnosed with one of 18 cancers from 322 population-based registries in 71 countries. Lancet 391: 1023-1075. [Crossref]

3. National Lung Screening Trial Research Team, Aberle DR, Adams AM, Berg CD Black WC, et al. (2011) Reduced lung-cancer mortality with low-dose computed tomographic screening. N Engl J Med 365: 395-409.

4. Moyer VA, US. Preventive Services Task Force (2014) Screening for lung cancer U.S. Preventive Services Task Force recommendation statement. Ann Intern Med 160: 330-338. [Crossref]

5. Decision Memo for Screening for Lung Cancer with Low Dose Computed Tomography (LDCT) (CAG-00439N). CMS.gov.

6. U.S. Department of Health and Human Services (2010) Patient Protection and Affordable Care Act, 2010. In.

7. Lung Force (2015) Is lung cancer screening covered under your insturance? In American Lung Association. 
8. Jemal A, Fedewa SA (2017) Lung Cancer Screening With Low-Dose Computed Tomography in the United States-2010 to 2015. JAMA Oncol 3: 1278-1281. [Crossref]

9. Gressard L, DeGroff AS, Richards TB, Melillo S, Kish-Doto J, et al. (2017) A qualitative analysis of smokers perceptions about lung cancer screening. BMC Public Health 17: 589.

10. Mishra SI, Sussman AL, Murrietta AM, Getrich CM, Rhyne R, et al. Patient perspectives on low-dose computed tomography for lung cancer screening, New Mexico, 2014. Prev Chronic Dis 13: E108.

11. Ersek JL, Eberth JM, McDonnell KK, Strayer SM, Sercy E, et al. (2016) Knowledge of, attitudes toward, and use of low-dose computed tomography for lung cancer screening among family physicians. Cancer 122: 2324-2331.

12. Hoffman RM, Sussman AL, Getrich CM, Rhyne RL, Crowell RE, et al. (2015) Attitudes and Beliefs of Primary Care Providers in New Mexico About Lung Cancer Screening Using Low-Dose Computed Tomography. Prev Chronic Dis 12: E108.

13. Raz DJ, Wu GX, Consunji M, Nelson R, Sun C, et al. (2016) Perceptions and utilization of lung cancer screening among primary care physicians. $J$ Thorac Oncol 11: 18561862.

14. Lewis JA, Petty WJ, Tooze JA, Miller DP, Chiles C, et al. (2015) Low-Dose CT Lung Cancer Screening Practices and Attitudes among Primary Care Providers at an Academic Medical Center. Cancer Epidemiol Biomarkers Prev 24: 664-670.
15. Triplette M, Kross EK, Mann BA, Elmore JG, Slatore CG, et al. (2018) An Assessment of Primary Care and Pulmonary Provider Perspectives on Lung Cancer Screening. Ann Am Thorac Soc 15: 69-75. [Crossref]

16. Kanodra NM, Pope C, Halbert CH (2016) Primary Care Provider and Patient Perspectives on Lung Cancer Screening. A Qualitative Study. Ann Am Thorac Soc 13 1977-1982. [Crossref]

17. Eberth JM, McDonnell KK, Sercy E, Khan S, Strayer SM, et al. (2018) A national survey of primary care physicians: Perceptions and practices of low-dose CT lung cancer screening. Prev Med Rep 11: 93-99.

18. Khairy M, Duong DK, Shariff-Marco S, Cheng I, Jain J, et al. (2018) An Analysis of Lung Cancer Screening Beliefs and Practice Patterns for Community Providers Compared to Academic Providers. Cancer Control 25: 1.

19. Klabunde CN, Marcus PM, Han PK, Richards TB, Vernon SW, et al. (2012) Lung cancer screening practices of primary care physicians: results from a national survey. Ann Fam Med 10: 102-110. [Crossref]

20. Hunt B, Balachandran B (2015) Black: White disparities in lung cancer mortality in the 50 largest cities in the United States. Cancer Epidemiol 39: 908-916.

21. Duong DK, Shariff-Marco S, Cheng I, Naemi H, Moy LM, et al. (2017) Patient and primary care provider attitudes and adherence towards lung cancer screening at an academic medical center. Prev Med Rep 6: 17-22.

22. Mazzone PJ, Tenenbaum A, Seeley M, Petersen H, Lyon C, et al. (2017) Impact of a Lung Cancer Screening Counseling and Shared Decision-Making Visit. Chest 151: $572-578$.

Copyright: (C2019 Meng-Hua T. This is an open-access article distributed under the terms of the Creative Commons Attribution License, which permits unrestricted use, distribution, and reproduction in any medium, provided the original author and source are credited. 